
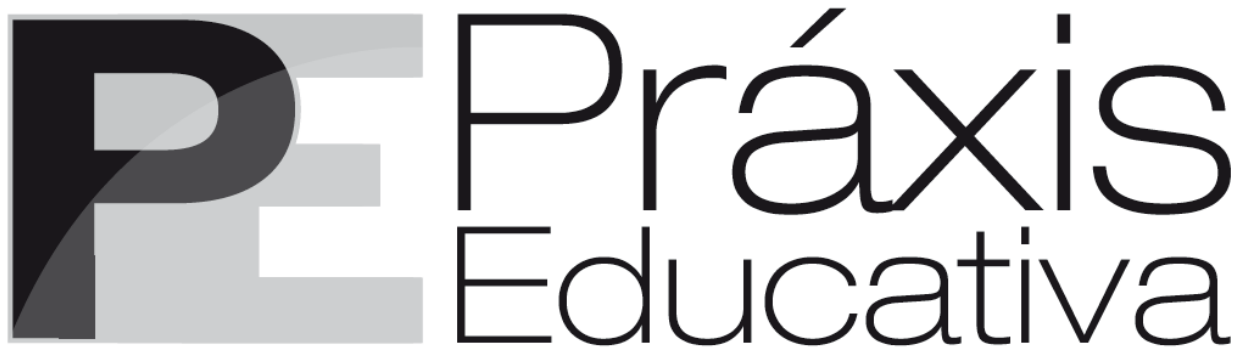

ISSN 1809-4031

elSSN 1809-4309

http://dx.doi.org/10.5212/PraxEduc.v.14n3.007

\title{
Cooperação, grupos identitários e participação democrática no Ensino Médio: o que pensam os professores?
}

\section{Cooperación, grupos identitarios y participación democrática en la enseñanza media: ¿qué piensan los profesores?}

\section{Cooperation, identity groups and democratic participation in High School: what do teachers think?}

\author{
Luiz Câmara* \\ Marcelo Andrade (in memoriam) ${ }^{* *}$
}

Resumo: $\mathrm{O}$ artigo apresenta os resultados de uma pesquisa que analisou como professores do Ensino Médio compreendem as relações entre seus estudantes e suas articulações com a formação ética e moral e com as diferenças identitárias, valorizando tanto a construção da autonomia, bem como as experiências de resistência democrática no espaço escolar. Como referencial teórico se recorre às contribuições de Alasdair MacIntyre, Adela Cortina e Angel Pérez Gómez. Como procedimentos metodológicos foram utilizadas as observações de campo e entrevistas semiestruturadas. Conclui-se que a cooperação e a presença de grupos são as principais características dessas relações, vivenciadas como experiências de autonomia pessoal e de resistência democrática no espaço escolar. A pesquisa revelou, ainda, que mesmo valorizando estas características, os professores entrevistados apresentam reflexões teóricas pouco elaboradas sobre a construção das identidades juvenis. Como consequência são promovidos baixos investimentos em ações pedagógicas, que valorizem a autonomia juvenil e a resistência democrática no espaço escolar.

Palavras chave: Participação democrática na escola. Cooperação. Grupos identitários.

Abstract: This paper brings the research results that analyzed how high school teachers comprehend the relations between their students and their articulations with ethical and moral formation and with the identity differences, enhancing both the autonomy building and the democratic resistance experiences in the school. As the theoretical reference, the contributions of Alasdair MacIntyre, Adela Cortina and Angel Pérez Gómez are referred. As the methodological procedures, field observations and semi-structured interviews were used. It was concluded that cooperation and groups presence are the main characteristics of such relations, lived as personal autonomy and democratic resistance experiences in the school. This research has also revealed that, even enhancing such characteristics, the interviewed teachers present low-

*Professor da Faculdade de Educação da UFRJ e coordenador pedagógico do Colégio Recanto do Fazer de Nova Iguaçu. E-mail: <luizccamara@hotmail.com>. ORCID: https://orcid.org/0000-0003-3744-4492

** Foi professor do Departamento de Educação da PUC-Rio e Coordenador do Grupo de Estudos sobre Cotidiano, Educação e Culturas (GECEC). 
elaborated theoretical reflections about youth identities construction. As a consequence, low investments are promoted for pedagogical actions that enhance youth autonomy and democratic resistance in the school.

Keywords: Democratic participation in school. Cooperation. Identity groups.

Resumen: El artículo presenta los resultados de una investigación que analizó cómo los profesores de enseñanza media comprenden las relaciones entre sus estudiantes y sus articulaciones con la formación ética y moral y con las diferencias identitarias, valorando tanto la construcción de la autonomía como las experiencias de resistencia democrática presentes en el espacio escolar. Como referencial teórico, se recurre a las contribuciones de Alasdair MacIntyre, Adela Cortina y Angel Pérez Gómez. Como procedimientos metodológicos fueran utilizadas las observaciones de campo y entrevistas semiestructuradas. Se concluye que la cooperación y la presencia de grupos son las principales características de dichas relaciones, vividas como experiencias de autonomía personal y de resistencia democrática en el espacio escolar. La investigación ha revelado todavía que, aún valorando esas características, los profesores entrevistados presentan reflexiones teóricas poco elaboradas sobre la construcción de las identidades juveniles. Como consecuencia, se promueve bajas inversiones en acciones pedagógicas que valoren la autonomía juvenil y la resistencia democrática en el espacio escolar.

Palabras clave: Participación democrática en la escuela. Cooperación. Grupos identitarios.

\section{Introdução}

Democratizar a escola não é, exatamente, uma temática nova no campo educacional, ainda que uma demanda urgente e necessária. Diferentes autores, como Vera Maria Candau (2008, 2010, 2016), defendem a necessidade de se "reinventar a escola" sob os signos da democracia e dos direitos humanos. Sem uma perspectiva democrática, a instituição tem o seu futuro fortemente questionado: “a escola tem futuro?”, já se perguntavam tanto Marisa Vorraber Costa (2003) quanto Rui Canário (2006) há uma década. Se não for para ser um espaço aberto, crítico, autônomo e democrático, qual seria a função social da escola nas sociedades contemporâneas? Segundo Angel Pérez Gómez (2001, p. 58), democratizar a escola, em uma sociedade neoliberal, significa superar a concepção de democracia como um procedimento meramente formal e defender um processo de permanente construção, para "enfrentar, mediante o diálogo, a informação compartilhada, o debate, a decisão majoritária, os inevitáveis conflitos no mundo da vida".

É com esta perspectiva sobre a democratização da escola que este artigo apresenta os resultados de uma pesquisa qualitativa ${ }^{1}$, que teve como objetivo analisar como professores do Ensino Médio de uma escola pública, de grande porte (2.000 estudantes e 120 professores),localizada no Município do Rio de Janeiro, percebem e compreendem as relações que se estabelecem entre seus estudantes e como essas relações se articulam e desafiam suas próprias formações éticas e morais, com ênfase nas diferenças identitárias presentes no espaço escolar. Por se tratar de uma investigação que envolve seres humanos em suas interações, o projeto de pesquisa foi submetido à Câmara de Ética em Pesquisa da Pontifícia Universidade Católica do Rio de Janeiro e obteve parecer favorável.

Como principais referenciais teóricos para as análises éticas e morais se recorre às abordagens dos filósofos Alasdair MacIntyre e Adela Cortina. O primeiro, herdeiro do pensamento aristotélico, é pesquisador do Centro de Estudos Contemporâneo em Ética e Política da Universidade Metropolitana de Londres, Inglaterra. A segunda, herdeira da filosofia

${ }^{1}$ A pesquisa contou com financiamento da CAPES e da FAPERJ.

Práxis Educativa, Ponta Grossa, v. 14, n. 3, p. 938-954, set./dez. 2019 Disponível em: <http://www.revistas2.uepg.br/index.php/praxiseducativa> 
kantiana e da ética do discurso, é Catedrática de Moral e Ética na Universidade de Valencia, Espanha. Ambos discutem e apresentam questionamentos a algumas das principais fundamentações éticas e morais construídas a partir da modernidade. Defendem uma abordagem radical da democracia que permite entender a educação escolar como uma das possibilidades de superar determinados limites das sociedades contemporâneas. Como principal referencial teórico para se analisar a democratização da escola hoje, utilizam-se os escritos de Angel Pérez Gómez, Catedrático de Didática e Organização Escolar da Universidade de Málaga, Espanha, sobre currículo e cultura escolar.

Como procedimentos metodológicos, procura-se articular duas estratégias de pesquisa, a observação de campo e a entrevista. Busca-se, entretanto, proceder à articulação da empiria com os referenciais teóricos com cuidado e vigilância, levando em conta sua adequação ao problema investigado e às condições de utilização de cada procedimento de coleta de dados. Durante um ano letivo, foram observadas as interações entre os estudantes e entre esses e seus professores, principalmente, nos horários do recreio e durante as aulas. Durante as observações foi possível perceber que, no geral, os estudantes aparentemente se relacionam bem. Não foi presenciado um clima permeado por conflitos explícitos e/ou com expressões de violência física, mas um ambiente no qual os estudantes aparentam trocar ideias e partilhar interesses e descobertas.

Foram entrevistados 17 docentes (11 professoras e seis professores), com idades variando entre 30 e 67 anos, selecionados aleatoriamente, a partir de sua disponibilidade, tendo como critério de convite a variedade das disciplinas lecionadas no Ensino Médio. Assim, a pesquisa busca entrevistados/as de todas as áreas curriculares presentes no Ensino Médio regular da escola pesquisada. O roteiro de entrevista foi elaborado com questões que abordavam: (i) a experiência docente; (ii) a percepção e compreensão dos professores sobre relações entre os estudantes; (iii) as principais características dessas relações. Considera-se que investigar o clima e as inter-relações entre os estudantes - através de observação direta e da percepção dos professores/as - pode ajudar a entender algumas experiências de desenvolvimento da autonomia pessoal entre os jovens, bem como experiências de resistências coletivas e de democratização no espaço escolar, cumprindo de maneira adequada os objetivos da pesquisa.

Em um primeiro momento, os professores foram unânimes em afirmar que, em geral, os estudantes se relacionam bem e descreveram o relacionamento como algo positivo, muito saudável, destacando que "algumas turmas são extremamente unidas" (Cristiano ${ }^{2}$ ). Para a descrição e análise das principais características dessas relações, segundo a visão dos entrevistados, os depoimentos foram organizados em diferentes categorias. No entanto, para a apresentação deste artigo se destacam aqui notadamente duas categorias: (i) o clima de cooperação e (ii) a ocorrência de conflitos e rivalidades a partir da formação de grupos. A opção por essas categorias se deve, principalmente, (i) por considerar que essas dialogam com as temáticas relacionadas com a construção da autonomia moral dos jovens estudantes; (ii) por possibilitar melhor entendimento sobre a democratização da escola; (iii) por indicar propostas e práticas curriculares que assinalam nesta perspectiva.

Nesse sentido se faz necessário justificar porque, a juízo da pesquisa, cooperação e conflito são categorias esclarecedoras sobre o que se está considerando como processos de democratização da escola e desenvolvimento da autonomia dos jovens no espaço escolar, bem como suas relações com propostas e práticas curriculares.

2 Todos os nomes utilizados são fictícios, respeitando o anonimato dos entrevistados, garantido aos mesmos através do Termo de Consentimento Livre e Esclarecido utilizado na pesquisa.

Práxis Educativa, Ponta Grossa, v. 14, n. 3, p. 938-954, set./dez. 2019 Disponível em: < http://www.revistas2.uepg.br/index.php/praxiseducativa > 
Assim, utilizam-se algumas conceituações de Angél Pérez Gómez (2001, p. 59-60) sobre a democracia e, especial, sobre a democratização da cultura escolar. Segundo o autor, em primeiro lugar, a democracia é um processo fundamental na e para a defesa da pluralidade e da tolerância, "contra a imposição de uma única ou melhor forma de pensar e de ser". Nesse sentido, a democracia - por mais imperfeita e inacabada que seja - é ainda a melhor disposição na defesa da diversidade e do respeito às diferenças, incluindo aí a escola, enquanto instituição social, comprometida com tais princípios. No entanto, e este é o segundo ponto defendido pelo autor, a democracia - especialmente como experiência no espaço escolar - não pode se reduzir a meros procedimentos formais; a escola "é uma forma de vida que inunda os esquemas de pensamento, de sentimento e de conduta dos indivíduos e dos grupos humanos". Seus valores mais fortes, indo além da pluralidade e da tolerância, são a defesa da igualdade e da solidariedade entre indivíduos e grupos diferentes que precisam ordenar sua convivência social.

Em terceiro lugar, Angel Pérez Gómez (2001) defende que em uma democracia há que se realizar a distinção entre a dignidade da pessoa e a validade de suas ideias. As pessoas são sempre respeitáveis, tal como também defende Adela Cortina (2003, 2013), mas as ideias podem e devem ser sempre debatidas e questionadas. É esta distinção que, por um lado, garante o respeito a todas as legítimas diferenças humanas e, por outro, mantém a democratização das instituições sociais em um processo vivo e dinâmico.

Em quarto lugar, para se democratizar uma instituição - em especial, a escola - deve-se estimular o interesse intelectual por aquilo que se desconhece e é objeto de discordância. Romper com o "egocentrismo epistemológico" e com a "indiferença diante do novo" é, sem dúvida, um desafio para a democratização da escola hoje e que os professores tão bem conhecem.

Em quinto lugar, apoiado nas concepções da ética do discurso, o autor defende que a democracia só pode se desenvolver mediante um "intercâmbio comunicativo". O diálogo não é só um procedimento argumentativo, mas o próprio conteúdo da democracia. Não há saída democrática sem a construção do diálogo em condições de igualdade e de oportunidade. Se não ocorrer em condições de igualdade e de oportunidade, o diálogo pode se tornar mero artifício e acabar por se desqualificar, bem como tornar desacreditada a experiência da democracia.

Por fim, Angel Péres Gómez (2001, p. 60) defende o "debate público permanente sobre as decisões que afetam a coletividade". Processos de democratização não cessam nunca; são contínuos e sempre anseiam por mais. Democracia demanda mais democracia e, talvez, seja este o seu caráter mais perturbador para os setores conservadores que hoje atacam a escola.

Adela Cortina (2003, p. 93, grifos da autora), em síntese e corroborando Angel Pérez Gómez (2001), define a "democracia radical e participativa" como uma "forma de vida valiosa por si mesma":

\begin{abstract}
De tudo isso se deriva que das distintas correntes do pensamento crítico e participativo convém considerar a democracia, não como um instrumento a serviço de fins privados, senão como uma forma de vida valiosa por si mesma, posto que respeita e fomenta o caráter autolesgislador dos indivíduos, potencializa neles o sentido da justiça, ao considerarlhes capazes de se orientar por interesses generalizáveis, e não somente por interesses individuais e grupais, e é por isso fonte de autorrealização ${ }^{3}$.
\end{abstract}

Neste sentido, a cooperação e o conflito - apresentados neste artigo como categorias analíticas a partir do depoimento dos professores - estão, segundo a análise, profundamente correlacionados com uma concepção de "democracia radical e participativa" (CORTINA, 2003,

\footnotetext{
${ }^{3}$ Todas as citações de Adela Cortina formas feitas pelos autores.
} 
2013), pois "esta forma valiosa em si mesma" entrelaça (i) a defesa da pluralidade e da tolerância; (ii) uma maneira de entender os sentimentos, os pensamentos e as condutas; (iii) a distinção entre o respeito à dignidade humana e as críticas às ideias; (iv) o interesse intelectual pelo desconhecido e pelo discordante; (v) o diálogo como procedimento democrático e como princípio ético e moral; (vi) o debate público e permanente (PÉREZ GÓMEZ, 2001).

Considerando, então, a temática da pesquisa, seus objetivos e procedimentos metodológicos e suas opções teóricas, veja-se - segundo o depoimento dos professores entrevistados - dois achados de pesquisa que levam a ampliar algumas concepções sobre a democratização da escolha hoje, a saber: a cooperação e os conflitos.

\section{"Um faltou, o outro vai dar a tarefa"}

O clima de cooperação foi apresentado pelos entrevistados como uma importante característica das relações entre os estudantes e foi destacado como o aspecto mais positivo do corpo discente. Os professores apontaram que a cooperação pode ser percebida, quando algum colega se ausenta e os outros lhe prestam informações sobre o que ocorreu na aula, entregando os materiais de estudo e se propondo a ir até a residência daquele/a que faltou para prestar algum apoio necessário. Segundo Marta: "um faltou, o outro var dar a tarefa. Um está doente, eles vão, levam na casa do colega esse trabalho. [...] Não é nem a familia que vem aqui buscar, é sempre o colega que leva".

Mesmo considerando a cooperação um aspecto positivo presente nas relações entre os estudantes, ao serem estimulados a responder sobre a importância desse comportamento, os professores apresentaram uma reflexão pouco elaborada sobre sua importância e sobre o seu significado nas relações cotidianas da escola. Caberia enfatizar que a indicação do valor da cooperação como algo importante e a ausência de uma reflexão mais elaborada sobre sua presença, nas relações pessoais entre os estudantes, chamou a atenção, pois se pressupunha que os professores, de alguma forma, iriam abordar essa questão a partir de alguns elementos mais reflexivos ou valorativos, posto ser a cooperação uma das características e requisitos fundamentais para a formação da autonomia moral e da democracia. Também chama a atenção as poucas referências sobre o papel que a escola poderia cumprir na constituição de relações mais cooperativas. Assim, a cooperação aparece como algo importante, mas não é explicitamente significada de sentidos e nem indicada como parte do papel formativo da escola, sendo considerada espontânea (ou seja, não incentivada por uma ação pedagógica específica da escola) e pouco significativa (ou seja, sem argumentos mais elaborados para justificá-la).

A apresentação de uma reflexão pouco elaborada, por parte dos entrevistados, sobre a presença da cooperação nas relações entre os estudantes poderia ser também interpretada como uma limitação formativa, ou seja, eles são capazes de perceber sua presença e importância nas relações entre os estudantes, mas não possuem elementos suficientes para elaborar uma reflexão mais aprofundada sobre a cooperação e suas relações com o desenvolvimento moral dos estudantes e os processos de democratização no espaço escolar. Por outro ponto de vista, poderia ser decorrente de uma limitação do instrumento de coleta de dados, ou seja, talvez os professores possuam tais concepções teóricas e uma reflexão mais profunda sobre o papel e a importância da cooperação, porém talvez o roteiro de entrevista não tenha sido capaz de captar essa reflexão. Levanta-se essa hipótese não por uma pseudo humildade como pesquisadores, mas pelo fato de que todo instrumento de pesquisa tem limites e esses devem ser considerados na análise dos dados.

É importante ressaltar que, segundo Cortina (2007), só se coopera quando há o reconhecimento do outro como semelhante, que possui necessidades dignas de serem supridas e 
se acredita que cabe a cada um, em condições de contribuir para a satisfação dessas necessidades, fazê-lo.

Seguindo a análise da filósofa espanhola, é possível afirmar que a cooperação pode ser motivada tanto pelos afetos presentes nas relações de amizade, como pela consciência de que é o certo a se fazer, ou seja, por um dever moral. Embora podendo não estar necessariamente explícita para aquele que coopera, é a motivação que define a amplitude das atitudes cooperativas, pois se o que a move é o sentimento de afeto pelos amigos ou familiares, será exclusivamente na relação com esse círculo restrito que a cooperação se fará presente. Todavia, se o que motiva é uma concepção de que se deve cooperar com o outro, sempre e quando se está ao alcance fazêlo, não importará a quem se dirige a atitude cooperativa, sendo extensiva a todo aquele que dessa necessitar, o que lhe daria um caráter mais ético e reflexivo.

Analisando, mais cuidadosamente, os dois tipos de motivações para a cooperação é possível relacionar o primeiro a uma fundamentação moral baseada nos "sentimentos sociais" de simpatia e benevolência, e o segundo a uma fundamentação moral baseada no princípio racional da autonomia.

Conforme Adela Cortina (2007, 2013), todas as sociedades admitiriam a existência de ações, de sentimentos e de características que devem ser louvados como virtudes e de outros que devem ser desaprovados como vícios. Argumenta que, nessa abordagem, é o sentimento de simpatia para com os afetados por males e bens, que torna possível essa distinção entre virtudes e vícios, entre, por exemplo, a justiça e a injustiça. A virtude da justiça, central para a convivência, é - a partir da visão de Hobbes e Maquiavel - valorizada pelo interesse de preservação da vida e da propriedade. Entretanto, com o crescimento das sociedades, algumas injustiças podem não afetar diretamente os interesses de pessoas. O que justificaria, então, esse sentimento de reprovação? Para os filósofos dos "sentimentos sociais" seria o sentimento de simpatia, que permite transitar da "obrigação natural" [baseada no interesse mais forte] para a "obrigação moral". Assim, seriam "os sentimentos sociais os que mantêm moralmente a sociedade" (CORTINA, 2007, p. 84).

Para Cortina (2007), esse tipo de abordagem possui cinco limites que devem ser explicitados. Primeiro: a posse de virtudes não geraria somente um sentimento agradável e uma consciência complacente, mas também uma boa reputação, do mesmo modo que sua ausência uma má reputação. Como consequência, o desejo de estima e reputação pode induzir as pessoas a realizarem determinadas ações que pareçam virtuosas, com o objetivo único de obter reconhecimento social e fama. Nesse sentido, adverte Cortina (2007, p. 95), se "o que nos impulsiona a agir moralmente é o afã de reputação e boa imagem, então o conservadorismo é insuperável e a moral, inexistente”.

Segundo: o sentimento de simpatia e de benevolência pode ser fonte de felicidade e bemestar, mas é mais forte ao ser dirigido a familiares e amigos, enfraquecendo-se ao se distanciar destes, pois: "quando eles se tornam amigos eles são amigos mesmo, para o que der e vier. Quando ele conquista a afeição do outro ele ajuda no que pode e até no que não pode, como acobertar alguma coisa errada, mas são amigos para o que der e vier" (Tina).

Terceiro: em sociedades multiculturais não basta se colocar no lugar do outro, tendo o sentimento de simpatia por sua situação, mas efetivar um diálogo com os afetados, porquanto os estilos de vida e concepções de bem-estar são muito diferentes, de acordo com as culturas e as identidades, que os distintos grupos partilham internamente e compartilham na convivência social mais ampla. 
Quarto: a ideia de justiça, compreendida como "dar a cada um o que lhe corresponde", pressupõe o reconhecimento de um direito ou necessidade e não pode se basear apenas na simpatia, porque esse não é um sentimento que requer reciprocidade.

Quinto: ao atribuir um papel secundário à razão, entendendo que a moralidade é menos julgada do que sentida, os partidários dos sentimentos sociais partem de uma concepção limitada de razão. Argumentam que a razão não tem o poder de mover a vontade, mas apenas de buscar os meios mais adequados para se alcançarem as metas definidas pelas paixões. Desconsideram, igualmente, que é a razão que reconhece e distingue as virtudes dos vícios e tem papel ativo, ao lado dos sentimentos, nas escolhas morais. No entanto, na pesquisa realizada, a moralidade parece ser fundamentada e sentida, uma vez que a cooperação por amizade foi o aspecto mais destacado pelos entrevistados.

O segundo tipo de motivação para a cooperação, como já mencionado, que se dirige a todo e qualquer um que dessa necessite, está vinculada a uma fundamentação ética e moral baseada no princípio racional da autonomia, compreendida como a capacidade de outorgar leis a si mesmo e de se auto-obrigar a cumpri-las. Cortina (2007) ressalta que essas leis não podem ser individuais, o que seria um contrassenso, pois não devem basear-se em motivações individuais ou egoístas, mas ter como referência a dignidade humana, partilhada e merecida por todos. Como consequência, a autonomia possui dois lados: a capacidade de se obrigar a cumprir as leis e de fazer opção por leis que expressem os interesses da humanidade, o que requer que se reconheça "a existência de um ideal de humanidade, pelo qual nos sentimos e nos sabemos vinculados, um ideal do qual brotam as leis" (CORTINA, 2007, p. 105).

Há, portanto, um duplo vínculo implicado no princípio da autonomia, o vínculo consigo mesmo e com toda a humanidade. Ligação que tem como ponto de partida, segundo Cortina (2007), o reconhecimento do caráter reflexivo, autoconsciente da mente humana. Este tipo de argumento defende que os desejos humanos fazem pressão para que sejam atendidos, mas como não se pode satisfazer a todos, busca-se através da reflexão - através de razões - discernir qual desejo se considera que seja bom para se tornar uma ação, que desejo possa querer como um princípio passível de ser seguido por qualquer pessoa.

Para Cortina (2007), este tipo de argumentação desconsidera outros elementos que também fazem parte da constituição do ser humano e que podem contribuir com suas escolhas. Um destes elementos é a identidade moral, que faz com que em decisões alguns aspectos sejam priorizados e outros relegados, que leva o ser humano a preferir determinados valores e a rechaçar outros, que possibilita avaliar o mundo de um ponto de vista moral e agir em decorrência dessa avaliação.

A identidade moral não e aquela que está expressa em um documento e possui efeitos civis, mas a que define, de alguma maneira, o horizonte do mundo moral de uma pessoa, de modo que a partir dessa identidade, o sujeito sabe o que é verdadeiramente importante para ele, o que lhe preocupa profundamente, como também aquilo que para ele não tem o menor significado (CORTINA, 2007, p. 111).

Articulada a essa perspectiva, Elza declara em sua entrevista que: "o cara pode ser homossexual, dentro da escola, pode ser negro, pode ser branco, e dá a impressão que eles falam todos, o mesmo idioma". A essa visão se somam as exigências do reconhecimento e a sensibilidade para com as diferenças, o que permite "reconhecer a alteridade, reconhecer 'os outros', e, como consequência, reconhecer sua identidade, que parta das diferenças, mais que da homogeneidade" (CORTINA, 2007, p. 111). 
Outro elemento que faz parte da bagagem moral do ser humano e é fruto da sensibilidade é a consciência moral, ou seja, a consciência de que a razão estabelece princípios a serem seguidos. Para Cortina (2007), o ser humano não é só reflexão e autoconsciência racional, mas possui algumas dimensões da sensibilidade sem as quais não seria capaz de reconhecer um sentimento de obrigação, tal qual relatam os entrevistados sobre seus estudantes. Entram na constituição desta consciência moral, os sentimentos morais e o sentimento de respeito por si mesmo e pelos outros. Acredita-se que, com esta argumentação, a autora deseje enfatizar os limites de uma concepção de moralidade baseada em uma razão puramente formal e desenraizada do mundo real, do mundo vivido, de um mundo em que o ser humano é também vulnerável e não apenas digno de respeito em função de sua dignidade, mas, por que não, de compaixão e benevolência, quando em situação de sofrimento: "um está doente, eles vão, levam na casa do colega esse trabalho".

Segundo o depoimento dos professores, a cooperação entre os estudantes não é caso isolado, iniciativa de uns poucos, mas um princípio construído e observado na escola investigada, o que leva a concluir que se trata de sinal claro da autonomia a ser desenvolvida nas práticas escolares.

Entretanto, merece ser enfatizado que, apesar de considerarem a cooperação uma característica importante das relações entre os estudantes, os professores entrevistados não explicitaram seu papel na promoção e na manutenção da coesão do grupo de estudantes. Entretanto, pode-se supor, a partir de algumas de suas falas, que esta coesão se faz presente e é valorizada. Marta, por exemplo, relata: "às vezes, eles vem até mim [e falam]: 'Marta, dá uma olhada no aluno tal, eu estou achando ele meio distante', ou porque está faltando, está com problema na familia, eles vêm até mim solicitar essa ajuda para um terceiro".

Esta coesão, segundo MacIntyre (2001), tem como importante fator um tipo particular de amizade. Ao propor, em sua crítica às diferentes tentativas modernas e contemporâneas de se fundamentar a moralidade, que se considere a possibilidade de um retorno a algumas ideias aristotélicas, o filósofo britânico adverte, entretanto, sobre o caráter diverso da compreensão aristotélica de amizade, distinto de seu entendimento no contexto liberal moderno individualista, dentro do qual foram relegadas as relações afetivas privadas nos tempos em que se vive.

Por esse prisma, as relações de cooperação entre os estudantes - aquelas que extrapolam as relações de amizade e afeto mais próximas - poderiam ser assim interpretadas, como uma expressão da virtude da amizade nesse sentido mais aberto, recuperado por MacIntyre (2001, p. 265) do pensamento aristotélico, como "o compartilhamento de tudo o que há em comum no projeto de criação e no sustento da vida da cidade, compartilhamento inserido no caráter imediato das amizades particulares de cada indivíduo". Nesse sentido, a cooperação pode ser vista como uma prática que fortalece os laços e vínculos entre os estudantes e, ao se darem conta de forma explícita, os professores poderiam promover intervenções que favoreçam experiências mais efetivas de democratização do espaço escolar, bem como de desenvolvimento da autonomia dos estudantes, tão fundamental para a ação cidadã nas democracias contemporâneas.

Todavia, nas falas dos entrevistados, não foram explicitadas tais intervenções, o que possibilita interpretar que os professores, embora reconheçam sua importância, não a expressaram como um conteúdo explícito de ensino e aprendizagem, embora tenha sido um comportamento aprovado e desejado em seus depoimentos. Talvez, a cooperação seja compreendida como aquele conjunto de aprendizagens comportamentais que os estudantes já deveriam ter adquirido, em suas famílias ou grupos sociais de referências, que é importante para a convivência escolar, mas que não deva se tornar objeto explícito dos processos de ensino e aprendizagem, o que certamente compromete uma visão mais crítica sobre as práticas 
curriculares, que escola hoje demanda. Vale destacar que, em hipótese alguma, se está defendendo que haja uma disciplina ou um conteúdo curricular para o ensino específico da cooperação, só se quer apontar que os entrevistados não a indicam, explicitamente, como parte do trabalho formativo, que eles próprios realizam junto aos jovens estudantes.

\section{"Acho que eles criam grupos"}

Outra categoria de análise destacada nos depoimentos dos professores foi a formação e a manutenção de grupos de afinidades, ou seja, os estudantes são unidos, têm relações próximas de amizade, mas restritas a um determinado grupo, não necessariamente a sua turma como um todo. Esses grupos, segundo a visão dos professores, geralmente, são formados por laços de proximidade ou por características comuns.

Entre eles eu acho que eles criam grupos, eles fazem grupos. Então, são várias tribos dentro de uma tribo maior que são os adolescentes. Então, têm os roqueiros, têm a galera que gosta de funks, têm os homossexuais, mas eles andam mais juntos. Os homossexuais masculinos, as femininas (Helen).

Assim como na discussão sobre a cooperação, os professores identificam uma característica importante presente nas relações juvenis dentro do ambiente escolar, mas ao serem questionados sobre o significado de tal característica, apresentaram uma reflexão pouco elaborada sobre a existência de grupos específicos entre os estudantes, bem como sobre os processos de formação e de manutenção dos mesmos no espaço escolar. Esse reconhecimento, sem um exercício reflexivo mais elaborado, talvez permita interpretar que os depoentes pouco conhecem ou pouco se atentam para relação entre a constituição de grupos e o processo de formação de identidades durante a juventude e as dinâmicas de democratização do espaço escolar, ou então, como apontado na discussão sobre a cooperação, não foi possível captar através das entrevistas realizadas, uma reflexão mais elaborada por parte dos depoentes, ainda que o roteiro de entrevista tenha valorizado tais aspectos.

Em que pese essa pouca elaboração, por parte dos entrevistados, sobre os grupos, vale destacar que a formação de grupos é um aspecto que merece atenção, posto que muitos autores (MELUCCI, 1997; TAYLOR, 2000; PÉREZ GÓMEZ, 2001; DAYRELL, 2003，2014; CORTINA, 2005, 2007) apontam para o importante papel dos agrupamentos entre pares na construção das identidades culturais e ajudam a compreender a importância e o valor da participação nesses grupos como um fundamento para a democratização da escola e, consequentemente, para práticas curriculares que façam da escola um espaço de resistência contra todo e qualquer tipo de autoritarismo.

A diversidade e o respeito às minorias são tão importantes na democracia como o
governo das maiorias. Neste sentido, convém ressaltar que a democracia deve se
defender ativamente contra a intolerância militante dos que querem impor uma única
forma de pensar e viver. A democracia requer uma disposição combativa a favor da
pluralidade e dos respeito às diferenças (PÉREZ GÓMEZ, 2001, p. 59).

Para Taylor (2000) e Cortina (2005, 2007, 2013), a identidade - principalmente aquelas consideradas socialmente minoritárias e diferentes - pode ser compreendida como o modo que cada um define a si mesmo e sua ausência configura uma crise pessoal, afetando sua saúde e integridade como pessoa, posto que é a identidade de cada um que "define de alguma maneira o horizonte de sua vida moral: o que realmente é importante para ela, o que lhe concerne profundamente e o que não lhe diz respeito" (CORTINA, 2005, p. 155).

Mas, qual o papel e a importância dos grupos na construção da identidade pessoal? Fazendo uma retomada histórica, Cortina (2005) lembra que nos tempos pré-modernos, a 
identidade de cada um era determinada antes de seu nascimento, em função de seu estamento social, o qual determinava se iria desfrutar ou não de "honra". Nesse sistema, a diferença estabelecida pelo nascimento se transforma em desigualdade social, pois somente os socialmente considerados superiores poderiam ser honrados. Não havia, portanto, nem construção, nem escolha da identidade por parte do indivíduo, posto que antes mesmo de seu nascimento, seu lugar e sua função social já estariam determinados.

$\mathrm{Na}$ modernidade, com o surgimento da ideia de dignidade, que pressupõe a igualdade entre os seres humanos, o conceito de honra herdada por nascimento perde sua força e a identidade não é mais imposta pelo local ou posição de origem, mas deve ser, por um lado, uma escolha pessoal e, por outro, resultado de um processo de construção individual que se dava ao longo da vida, mas, principalmente, durante a infância e a juventude, entendidas como aqueles períodos em que o sujeito se forma e se constrói. Nesse sentido se busca que a diferença de nascimento não se transforme em desigualdade legitimada pelo sistema social. Essa escolha, entretanto, não ocorre de forma isolada e autossuficiente, porque no processo de construção identitária, que exige uma tomada de consciência e de aceitação de suas características pessoais e históricas, há também a necessidade de reconhecimento dessas características por outras pessoas.

Cada pessoa deve, então, investigar sua identidade porque é ela quem deve aceitá-la. Mas, ao mesmo tempo, precisa [...] que os outros reconhecem sua identidade, sobretudo aqueles que foram denominados "outros significativos", que são os que importam para uma pessoa e ajudam a se autodefinir. [...] A identidade não nos é dada, mas a negociamos - daí a importância das lutas sociais empreendidas para obter $\mathrm{O}$ reconhecimento dos outros significativos (CORTINA, 2005, p. 156).

É nesse sentido que a livre escolha dos grupos de pertencimento ou grupos de afinidade é tão importante para a formação das identidades pessoais. Os grupos fornecem um sentido de pertença, que possibilita que os indivíduos elejam e redefinam suas identidades, ao mesmo tempo em que propiciam o necessário reconhecimento dessas escolhas. Tal processo é fundamental na juventude e, em especial, no espaço uma escola de Ensino Médio.

Ao se referirem aos diferentes grupos dos quais fazem parte os estudantes, os professores entrevistados especificam algumas características identitárias que lhes chamam a atenção. Os grupos, em geral, são formados em função de seus gostos musicais (rock e funk), de sua crença ou descrença religiosa (evangélicos, católicos e ateus), por sua orientação sexual (homossexuais masculinos e femininos), pelo lugar de moradia (Rocinha, Vidigal) ou apenas por relações de amizade, sem que alguma característica de identidade seja explicitada. Há também aqueles estudantes que não estão inseridos em nenhum grupo específico, que no espaço da escola ficam isolados, "que não se misturam com ninguém, são tímidos, preferem até fazer trabalho individual, não participam, ficam meio a parte" (Helen). Essa riqueza de grupos, segundo a análise, é fundamental para a aprendizagem com e pelas diferenças e para algumas possibilidades de se trabalharem perspectivas de democratização do espaço escolar.

Melucci (1997) e Dayrell (2003, 2014) observam o papel privilegiado dos grupos juvenis na constituição de suas identidades, pois se constituem enquanto espaços de ação, de reconhecimento e de convivência em uma coletividade em que eles têm a possibilidade de ampliar relações capazes de construir identidades positivas. Ressalvam, entretanto, que alguns grupos podem não cumprir esse fim, porém sugerem que tal potencialidade deveria ser incentivada por aqueles que trabalham com a formação de jovens e adolescentes, caso claro de professores que atuam no Ensino Médio. Para Melucci (1997, p. 09): "gêneros musicais, participação em grupos, funcionam como linguagens temporárias e provisórias com as quais o indivíduo se identifica a manda sinais de reconhecimento para os outros”.

Práxis Educativa, Ponta Grossa, v. 14, n. 3, p. 938-954, set./dez. 2019 Disponível em: <http://www.revistas2.uepg.br/index.php/praxiseducativa> 
Por outro lado, os entrevistados explicitaram, igualmente, uma preocupação com a dificuldade de relacionamento e entrosamento entre esses grupos, o que em alguns momentos, em sua visão, prejudica o bom andamento das atividades pedagógicas em sala de aula. Nessa perspectiva, para Olinda: "eles têm grupos fechados, alguns têm grupos fechados, na hora de fazer trabalho em grupo só querem fazer com determinado grupo. Ai se o outro quer entrar, não deixam...”. Assim, a noção de grupo parece positiva quando reflete a sociabilidade dos jovens, mas se torna um tema problemático, segundo alguns depoentes, quando os mesmos interferem no trabalho pedagógico realizado em sala de aula, o que leva a perceber que talvez eles sejam notados, principalmente, em função das atividades escolares e nem tanto como espaço de construção e de reconstrução das identidades juvenis (DAYRELL, 2003).

Em outros momentos, entretanto, é a presença de um bom entrosamento que prejudica o desenvolvimento das aprendizagens. Segundo os entrevistados, os grupos de afinidade também atrapalham, quando "exageram" nas brincadeiras e nas dispersões, em especial, naqueles momentos em que os professores desejam e necessitam da atenção da turma para as atividades pedagógicas. Olinda relata, ainda, que sempre propõe trabalhos em grupo, com o objetivo de contribuir com a socialização e a integração dos estudantes, o que demonstra sua preocupação com este aspecto da formação dos jovens. No entanto, essa contradição foi apontada: ora os grupos ajudam, ora os grupos atrapalham. Assim, parece que os grupos por afinidade, ao mesmo tempo, devem ser valorizados e controlados pelos professores. Valorizados porque permitem a construção de amizades e de convivências, apontando experiências democráticas na escola. Controlados, porque esses podem atrapalhar as atividades das práticas pedagógicas e curriculares no espaço escolar.

Nesse sentido, Dayrell (2003) adverte, a partir de pesquisa empírica realizada com jovens pertencentes a grupos musicais (rap e funk), que ao avaliarem suas experiências escolares, esses jovens consideram que a instituição escolar não valoriza suas expressões culturais e suas formas de organização, distanciando-se de seus interesses e necessidades. Assim, segundo o autor, os grupos entre pares são importantes para a formação de identidades, mas tal como parece indicar os depoimentos dos entrevistados, esses significam uma contradição no cotidiano da escola: ora valorados como experiência de socialização e democratização; ora como um estorvo para as práticas pedagógicas e curriculares.

Não obstante, os professores se mostraram preocupados com os conflitos e as rivalidades que se manifestam, em vários momentos, em sala de aula, quando, por exemplo, algum estudante é solicitado a apresentar sua opinião sobre determinado assunto e é logo interrompido por outro, antes mesmo de completar seu raciocínio. Essas rivalidades se expressam, segundo os depoimentos, por xingamentos, ofensas e pela falta de paciência com os diferentes ritmos e maneiras de realizar as atividades escolares.

Segundo os professores, o que se percebe, nesses casos, não é uma discordância de ideias, pois muitas vezes o raciocínio não é ouvido e compreendido, mas uma oposição à pessoa, um desejo de desqualificá-la a todo o momento, como sinaliza Ideia: "porque se um fala uma coisa, o outro já vêm e critica. Outras vezes, a resposta que eu dou, o outro: 'Ai, viu? Tomou um fora!' e en falo: Não, isso não é um fora', quer dizer, às vezes, eles não deixam nem o professor concluir, ele já está armado pra tentar ridicularizar o outro". Nessa perspectiva, parece não haver a distinção entre a dignidade humana e a saudável crítica às ideias, tal como já apresentado por Angel Pérez Gómez (2001). Há, portanto, uma necessidade pedagógica de se ensinar e aprender um dos princípios básicos da democracia: o respeito incondicional à pessoa humana e à crítica pertinente e justificada as ideias e conceitos que esta mesma pessoa defende.

Práxis Educativa, Ponta Grossa, v. 14, n. 3, p. 938-954, set./dez. 2019 Disponível em: <http://www.revistas2.uepg.br/index.php/praxiseducativa> 
Os professores apontaram também que, em alguns casos, essa rivalidade não surge dentro da escola, mas adentra a escola, a partir da comunidade de origem dos estudantes, o que pode estar demonstrando que o pertencimento a determinado grupo provoca, em alguns estudantes, uma resistência em conviver com aqueles grupos distintos do seu. Pode-se supor que o que está em jogo, nesses casos, é a dificuldade de se lidar adequadamente com a relação entre identidade e diferença.

Nesta perspectiva, ao mesmo tempo em que a agregação em grupos de afins é saudável e cumpre um papel fundamental na constituição da própria identidade e nas experiências de democratização do espaço escolar, pois a partir da partilha de características comuns as pessoas se reconhecem dentro de um grupo, por outro lado, pode provocar a negação daquelas identidades, que possuem características que não se compartilham e que estão presentes em outros grupos. Isto ocorre, geralmente, porque cada indivíduo, em seu processo de individuação, procura negar as outras comunidades, desconsiderando que nessas também há outros sujeitos na luta para construir e manter suas identidades (TRIAS, 2002).

Para os entrevistados, todavia, esses conflitos e dificuldades de aceitação da diferença ocorrem, com maior frequência, nas turmas do $1^{\circ}$ ano do Ensino Médio, o que pode ser interpretado como fruto da imaturidade e do estranhamento inicial no espaço da escola. "Não sei se é porque tem mais aluno de primeiro ano, que vem de escolas diferentes e se encontram aqui na escola. Então, eu acho que até um aceitar o outro leva certo tempo. Quando chega no segundo ano a gente tem menos problemas de disciplina, de rivalidade entre os alunos" (Lia).

Embora os professores não explicitem, essa diminuição dos conflitos e rivalidades nas turmas mais avançadas pode ser interpretada como resultado do amadurecimento pessoal, do maior entrosamento entre os diferentes grupos e do desenvolvimento de uma postura mais respeitosa com as diferenças, que reconhece a igualdade de dignidade de todos os grupos presentes no espaço escolar, o que revelaria grande potencial da escola para ampliar experiências de democratização. Por outro lado, não seria absurdo lembrar que, historicamente, a escola tem importante papel na uniformização das diferenças (CANDAU, 2008, 2011, 2016). Assim, quanto mais tempo na escola, ou seja, a partir do segundo ano de inserção na escola, os estudantes estariam mais adequados, mais normatizados às regras de convivência da escola. Vale ainda a hipótese de que os conflitos talvez diminuam em função da grande evasão escolar que o Ensino Médio enfrenta, no geral, e na escola pesquisada em particular, visto que um pouco mais de $50 \%$ dos que iniciaram o Ensino Médio chegaram a concluí-lo. Seriam os que permanecem na escola aqueles que mais bem se adéquam às exigências escolares e às regras de convivência da instituição? Não se pode responder tal questão com os dados que se têm, mas esses permitem, ao menos, formulá-la.

Ao defender que a escola promova junto aos estudantes habilidades que os capacitem a se tornarem membros reflexivos e independentes de suas famílias e comunidades, MacIntyre (2002) considera que a aprendizagem dessas virtudes é necessária para que os jovens consigam fazer escolhas que sejam boas para si e levem em conta o bem da coletividade. Ao contribuir com o pensamento reflexivo de seus educandos, os professores têm a possibilidade de lhes fornecer ferramentas para lidarem racional e emocionalmente com os conflitos oriundos de seus preconceitos e dificuldades de aceitação da diferença.

Em algumas entrevistas, a família foi responsabilizada pelos problemas de relacionamento entre os estudantes. $\mathrm{Na}$ visão dos entrevistados, os estudantes chegam à escola sem uma formação familiar, que lhes possibilite relacionar-se bem com os colegas e com seus professores. Tampouco, possuiriam uma disciplina pessoal que contribua com sua aprendizagem, como afirma Cravo: "Infeliz̧mente, as familias não estão sendo capažes disso, de dar essa formação, que já era pra 
gente receber com essa educação de como se comportar e tal, realmente você vê que eles não sabem". Por outro lado, os familiares (pais ou responsáveis) são frequentemente chamados à escola, para que tomem conhecimento dos problemas e adotem alguma medida, junto com a escola, para resolver problemas de comportamento dos estudantes.

Embora não apareça, de forma explícita, nas falas, ao afirmarem que os estudantes não possuem um comportamento adequado, que possibilite com que se relacionem bem e que contribua com a aprendizagem, os professores parecem estar supondo que os estudantes deveriam chegar à escola com uma formação de atitudes e de valores constituída, ou seja, com uma "formação moral pronta". Entretanto, não se pode deixar de considerar que o processo de escolarização se inicia (pelo menos obrigatoriamente) aos seis ou sete anos de idade e que a formação de valores e de atitudes é um processo que se inicia na infância e estende até a idade adulta, conforme as teorias mais consagradas da psicologia do desenvolvimento moral, elaboradas por Piaget e Kohlberg. Por outro lado, ao chegarem ao Ensino Médio, os estudantes já possuem, além de sua trajetória de vida familiar, no mínimo oito anos de escolarização, o que possibilita supor que a responsabilidade pela ausência ou presença de um comportamento adequado não pode ser creditada apenas às famílias, mas deveria também ser compartilhada com a escola.

Luca, entretanto, aponta para uma prática que parece mais produtiva do que a busca por culpados pelos problemas de comportamento e de relacionamento entre os estudantes: "Tinha um problema em uma turma, um aluno dando problema, ela [a diretora] chamava o responsável, chamava o pai, chamava o aluno, conversava, se comprometia, faria um pacto ali”. Nesse sentido, a busca por uma parceria e corresponsabilidade entre a escola e a família parece ser o melhor caminho a ser seguido, segundo a depoente, muito mais porque, neste caso, leva-se em conta que pais e professores precisam entrar em acordo sobre quais comportamentos e atitudes são necessários para que os estudantes adquiram experiências escolares significativas, seja do ponto de vista mais pedagógico e curricular, seja do ponto de vista das experiências de democratização desse espaço de convivência, de ensino e de aprendizagem.

\section{Considerações finais}

Embora se tenham destacado da fala dos professores (i) a relação de cooperação e amizade e (ii) a presença de diferentes grupos, alguns outros aspectos do relacionamento entre os estudantes foram apontados durante a investigação realizada. Destacam-se, a seguir, alguns outros aspectos, ainda que brevemente, a fim de situar ainda mais as duas categorias analíticas trabalhadas no artigo.

$\mathrm{Na}$ visão de alguns entrevistados, algumas relações entre os estudantes são superficiais, imediatas e individualistas e essas são permeadas por provocações e agressividade e a violência entre os jovens parece estar se banalizando. Há também a presença de lideranças, o que é avaliado tanto positivamente - quando chamam a atenção dos colegas nos momentos em que estão prejudicando o andamento das aulas - como negativamente - em momentos que suscitam brincadeiras e provocações, que dispersam a atenção dos colegas.

Abramo (1997) considera que o modo como a juventude é vista e compreendida socialmente sofreu importantes transformações nas últimas décadas. De uma juventude inerentemente predisposta à transgressão e à delinquência, materializada na imagem dos "rebeldes sem causa" nos anos cinquenta, passando por uma geração que representava uma ameaça da ordem social, política, cultural e moral a partir de uma postura crítica aos regimes autoritários, nos anos sessenta e parte dos setenta, a juventude passa a ser vista nos anos oitenta com 
características opostas às décadas anteriores: $\mathrm{O}$ individualismo, $\mathrm{O}$ consumismo, $\mathrm{O}$ conservadorismo e a apatia diante de questões políticas são suas marcas mais destacadas.

Nas últimas décadas, entretanto, na visão de Abramo (1997), outra mudança ocorre na visibilidade social da juventude, não sendo mais a apatia e o individualismo que se destacam, mas a presença de jovens, em atividades individuais e coletivas, nas ruas das grandes cidades, sendo destacados os grupos de meninos de rua, as gangues e os arrastões entre outras formas de questionamento da ordem social estabelecida na sociedade burguesa.

Fruto de uma situação anômala, da falência das instituições de socialização, da profunda cisão entre integrados e excluídos, de uma cultura que estimula o hedonismo e leva a um extremo individualismo, os jovens aparecem como vítimas e promotores de uma "dissolução do social". O pânico, aqui, se estrutura em torno da própria possibilidade de uma coesão social qualquer (ABRAMO, 1997, p. 32).

Caberia aqui, considerar, junto com Cortina (2005, p. 181), o papel dos valores que compõe uma ética cidadã - liberdade, igualdade, solidariedade, respeito ativo e diálogo - no enfrentamento do individualismo e do hedonismo, atribuídos como características do comportamento juvenil contemporâneo. Para a filósofa espanhola, esses são valores "que qualquer escola, pública ou privada, deve transmitir na educação, porque são os que durante séculos tivemos que aprender e que já fazem parte de nosso melhor tesouro". Tais valores, inclusive, são fundamentais para uma compreensão de democracia e de democratização da escola. Não são valores estáticos, mas dinâmicos, em permanente ressignificação.

Como exemplos de posturas solidárias e de respeito ativo, merece destaque o fato de a escola investigada possuir estudantes com deficiência incluídos nas turmas, os quais - segundo os depoentes - são muito bem recebidos pelos demais, que os auxiliam em suas dificuldades. Esse seria um importante aspecto para se entender as relações entre os estudantes com a diferença. No entanto, foi pouco mencionado pelos depoentes e, quando o foi, não houve considerações ou problematizações mais elaboradas sobre o tema, o que revela um campo de pesquisa a ser explorado.

Alguns professores indicaram, que as relações entre os estudantes não se restringem aos momentos em que estão juntos fisicamente, mas prosseguem no ambiente virtual por meio das diferentes redes sociais digitais, das quais alguns professores também fazem parte. Ainda que não tenha sido o objetivo desta pesquisa, vale destacar que as relações pessoais estão, cada vez mais, mediadas por outros ambientes, que não apenas o escolar, mas, sobretudo, o ambiente digital (SALES, 2014). Não se pode afirmar, mas se pode inferir, que cooperação, amizade, formação de grupos, rivalidades e conflitos são características que permeiam as relações juvenis da escola pesquisada, entre o cotidiano escolar e o mundo virtual, ampliando assim as experiências de democratização da escola e novas perspectivas de práticas curriculares, que adentram e extrapolam o ambiente escolar.

Após apresentar e analisar as falas dos professores entrevistados, sobre sua visão das relações que se estabelecem entre seus estudantes, é possível tirar algumas conclusões, mesmo que provisórias e parciais.

Considerando que a cooperação foi apresentada com uma importante característica dessas relações, que é considerada pelos professores como um aspecto positivo para convivência entre os estudantes, a reflexão teórica apresentada sobre seu papel na formação da identidade (TAYLOR, 2000; CORTINA, 2005, 2007, 2013; MELUCCI, 1997; DAYRELL, 2003, 2014) e para a coesão da comunidade de pertencimento (MACINTYRE, 2002; PÉREZ GÓMEZ, 2001), e ainda a ausência de uma reflexão mais aprofundada por parte dos docentes sobre sua 
importância, bem como a falta de relatos sobre ações e investimentos pedagógicos para sua promoção e valorização no espaço escolar, arrisca-se a concluir que há uma grande carência de espaços de discussão e de formação no ambiente escolar sobre tais temáticas. Ao serem priorizados os conteúdos programáticos de cada disciplina, os professores deixam de se atentar e investir em importantes e fundamentais aspectos da formação de seus estudantes, os quais poderão ter como uma de suas consequências uma aprendizagem mais significativa, posto que se os estudantes possuem uma prática cooperativa, em suas relações, têm a possibilidade de se ajudarem diante de suas dificuldades de aprendizagem.

Ao apontarem que a presença de grupos é outra importante característica das relações entre os estudantes, e também, ao mesmo tempo, não explicitarem uma reflexão mais elaborada sobre sua importância para a construção de suas identidades, os entrevistados não deixam claro que papel eles cumprem na formação ética e moral de seus estudantes, nem como os grupos reforçam experiências de democratização da escola, da sociedade e da vida em comum. Assim como apontado na discussão sobre a cooperação, pode-se novamente referir a uma ausência de espaços de troca de experiências docentes sobre as possibilidades de trabalhar com perspectivas de democratização de propostas e de práticas curriculares, que apontem nesta perspectiva.

Por um lado, os entrevistados parecerem compreender o papel e as características dos grupos juvenis para a formação de seus estudantes. Por outro lado, apresentam-se preocupados com a dificuldade de relacionamento e de entrosamento entre os diferentes grupos presentes no espaço escolar, os quais, segundo algumas falas, prejudicam o bom desenvolvimento das atividades pedagógicas em sala de aula. Sobre esta preocupação se pode supor que, se os docentes possuíssem mais espaços institucionais de reflexão sobre como se constituem os grupos, sobre a importância que a inserção em grupos tem para a constituição das identidades de seus jovens estudantes; sobre a negação das identidades que não compartilham as mesmas características do grupo de pertencimento; sobre os perigos de se desconsiderar que os outros, os diferentes, também estão em processo de construção e de manutenção de suas identidades, esses professores teriam mais segurança para intervir e contribuir para que os diversos grupos se relacionem, a partir do reconhecimento e do respeito por suas diferenças identitárias (TRIAS, 2002).

Para finalizar, considera-se importante apontar como um desafio para professores e gestores educacionais, a promoção de espaços docentes de formação - inicial e/ou continuada que, ao mesmo tempo, (i) sensibilize e prepare os professores para atuarem, pedagogicamente, para além dos conteúdos disciplinares; (ii) reflita sobre seu papel enquanto sujeitos comprometidos com a promoção de uma formação cidadã para uma convivência justa e democrática com os diferentes; (iii) entenda que os diferentes grupos de identidade devam ser reconhecidos e valorizados em sociedade plurais e democráticas; (iv) promova a prática da solidariedade e da cooperação como experiência de democratização do espaço escolar.

A formação docente e as práticas curriculares devem ser encaradas como uma reconversão do olhar, não apenas como mais uma função meramente técnica, mas como uma prática social, que envolve uma profunda compreensão sobre o que significa educar e formar cidadãos e grupos, que operam com a diferença e cooperam entre eles em sociedades, que se desejem plurais e democráticas.

\section{Referências}

ABRAMO, H. W. Considerações sobre a tematização social da juventude no Brasil. Revista Brasileira de Educação, Rio de Janeiro, n. 5-6, p. 25-36, maio/dez. 1997. 
CANÁRIO, R. A escola tem futuro? das promessas às incertezas. Porto Alegre: ArtMed, 2006.

CANDAU, V. M. Direitos humanos, educação e interculturalidade: as tensões entre igualdade e diferença. Revista Brasileira de Educação, Rio de Janeiro, v. 13, n. 37, p. 45-56, jan./abr. 2008. DOI: https://doi.org/10.1590/s1413-24782008000100005

CANDAU, V. M. Reinventar a escola. Rio de Janeiro: Vozes, 2010.

CANDAU, V. M. Diferenças culturais, cotidiano escolar e práticas pedagógicas. Currículo sem Fronteiras, v. 11, n. 2, p. 240-255, jul./dez. 2011.

CANDAU, V. M. F. Cotidiano escolar e práticas interculturais. Cadernos de Pesquisa, São Paulo, v. 46, n. 161, p. 802-820, set. 2016. DOI: https://doi.org/10.1590/198053143455

CORTINA, A. Ética aplicada y democracia radical. Madrid: Editorial Tecnos, 2003.

CORTINA, A. Cidadãos do mundo: para uma teoria da cidadania. São Paulo: Edições Loyola, 2005.

CORTINA, A. Ética de la razón cordial: educar en la ciudadanía en el siglo XXI. Oviedo: Ediciones Nobel, 2007.

CORTINA, A. ¿Para qué sirve realmente la ética?. Madrid: Paidós, 2013.

COSTA, M. V. A escola tem futuro?. Rio de Janeiro: Lamparina, 2003

DAYRELL, J. O jovem como sujeito social. Revista Brasileira de Educação, Rio de Janeiro, n. 24, p. 40-52, set./dez. 2003. DOI: https://doi.org/10.1590/s1413-24782003000300004

DAYRELL, J.; CARRANO, P. Juventude e Ensino Médio: quem é este aluno que chega à escola. In: DAYRELL, J.; CARRANO, P.; MAIA, C. L. (Orgs.). Juventude e ensino médio: sujeitos e currículos em diálogo. Belo Horizonte: Editora UFMG, 2014. p. 101-133.

MACINTYRE. A. Depois da virtude: um estudo em teoria moral. Baurú: EDUSC, 2001.

MACINTYRE. A. Alasdair MacIntyre on education: in dialogue with Joseph Dunne. Journal of philosophy of Education, v. 36, n. 1, p. 1-19, 2002. DOI: https://doi.org/10.1111/1467$\underline{9752.00256}$

MELUCCI, A. Juventude, tempo e movimentos sociais. Revista Brasileira de Educação, Rio de Janeiro, n. 5-6, p. 5-14, maio/dez. 1997.

PÉREZ GÓMEZ, A. A cultura escolar na sociedade neoliberal. Porto Alegre: ArtMed, 2001.

SALES, S. R. Tecnologias digitais e juventude ciborgue: alguns desafios para o currículo do Ensino Médio. In: DAYRELL, J.; CARRANO, P.; MAIA, C. L. (Orgs.). Juventude e ensino médio: sujeitos e currículos em diálogo. Belo Horizonte: Editora UFMG, 2014. p. 229-248.

TAYLOR, C. Argumentos filosóficos. São Paulo: Edições Loyola, 2000. 
Cooperação, grupos identitários e participação democrática no Ensino Médio...

TRIAS, E. Identidad cultural. In: CONIL, J. (Org.). Glossário para uma sociedade intercultural. Valencia: Bancaja, 2002. p. 78-82.

Recebido em 06/06/2018

Versão corrigida recebida em 23/06/2019

Aceito em 25/06/2019

Publicado online em 09/07/2019 